\title{
Giacomo Bartoloni 60 anos: uma reflexão sobre as narrativas de sua carreira no festival em sua homenagem
}

Fábio Bartoloni

Teresinha Prada

Recebido em 16/07/2018

Aprovado em 20/09/2018 
O artigo apresenta reflexões sobre o Festival Giacomo Bartoloni 60 Anos, ocorrido de 9 a 11 de agosto de 2017 no Instituto de Artes da Universidade Estadual Paulista Júlio de Mesquita Filho - UNESP, aproximando-se de teorias que sustentam a história e suas biografias construídas em narrativas, debatendo-se a trajetória desse docente e intérprete de músicas para violão de concerto, cujo trabalho composicional assume outra faceta em sua carreira e isso será aqui enfatizado. O evento seguiu o modelo de um festival de violão clássico para homenagear os 60 anos desse violonista, organizado por Gilson Antunes, Cleyton Fernandes, Fábio Bartoloni (ex-alunos), Gisela Nogueira e Luciano Morais (ex-colegas), com uma programação visivelmente planejada com o intuito do referido tributo ao violonista, no entanto, a ocasião propiciou debater a atividade artístico-cultural do meio erudito musical, a docência, incluindo o nível superior e o papel da universidade pública, bem como o retrato de uma geração que viu o violão passar de instrumento marginalizado a atuante na tradicional música de concerto.

Palavras-chave: narrativa histórica, música de concerto, violão clássico, docência.

\section{NARRATIVAS DE UMA TRAJETÓRIA MUSICAL}

O Festival Giacomo Bartoloni 60 Anos ocorreu de 9 a 11 de agosto de 2017 no Instituto de Artes da Universidade Estadual Paulista Júlio de Mesquita Filho (UNESP) para homenagear os 60 anos do violonista Giacomo Bartoloni. Seguindo o modelo de um festival de música erudita, ou seja, masterclasses, palestras, mesas e concertos, toda a programação' do Festival Giacomo Bartoloni 60 Anos (doravante chamado FGB) foi centralizada na trajetória desse paulistano. Esse ex-aluno de Henrique Pinto (1941-2010), Abel Carlevaro (1916-2001), Guido Santórsola (1904-1994) e Marília Pini (1937-) fundou

\footnotetext{
' Programação completa em https://www.scribd.com/document/369799889/Programac-ao-completa-do-Festival-Giacomo-Bartoloni-60-Anos
} 
em 1987 o Bacharelado em Violão na UNESP, onde alcançou a Livre-docência e o Doutorado em História. É intérprete de consolidada carreira, inclusive internacional, realizando o Duo Franco/Brésilien com Frédéric Bernard desde 1991, gravando uma dezena de CDs lançados na França. Como camerista, integrou o Violão Câmara Trio, gerando em 1989 um disco referencial para o violão ao lado de Henrique Pinto e Ângela Muner, além do Duo Bartoloni com o filho Fábio Bartoloni e o Quarteto Bartoloni, integrado pelos filhos Fábio, Bruno e Felipe Bartoloni. Outrossim, tivemos no FGB a chance de perceber seu trabalho de compositor premiado - algo que será exposto no presente texto.

Reconhecemos enlaces desse evento artístico-musical e acadêmico com teorias do filósofo francês Paul Ricoeur (19132005), especialmente em seu texto-chave Tempo e Narrativa de $1983^{2}$, posto que durante o FGB observamos, anotamos e gravamos relatos que, posteriormente, foram considerados para a feitura desse trabalho. Vamos iniciar pela conceituação da "narrativa histórica" de Ricouer e, ao final do artigo, nos aprofundaremos na composição de Bartoloni.

A análise historiográfica com Ricoeur encaminha-se pela narrativa, diferentemente dos modelos em voga que então seguiam um discurso supostamente neutralizado pelo uso de dados e documentos. De acordo com o historiador José Barros:

A frase lapidar de que "toda história é narrativa", pronunciada por Ricoeur no seio de uma historiografia francesa que durante décadas cultivara o discurso de desprezo em relação ao factual, ao biográfico, (...) invadiu como um raio inquietante a tranqüilidade celeste de uma historiografia.

(...) A consciência da narratividade (necessária) da História, reafirmada por Paul Ricoeur, apresenta implicações importantes, sendo a mais importante delas assegurar o retorno do vivido, da sensibilidade e da ação humana a uma historiografia que nos casos extremos parecia quase se abstrair do homem. (BARROS, 2012, p.2)

2Essa obra é o trabalho mais relevante de Ricouer, composta por três volumes, sendo que utilizamos aqui a mediação de historiadores especialistas em seus conceitos para abordar a Narrativa como descrição do que vimos nos relatos produzidos durante o FGB. 
A narrativa por Ricouer é uma trama constituída de diversos episódios e personagens ligados e justapostos ao enredo mais amplo, daí resultando uma totalidade significativa. A comissão organizadora, ao estabelecer uma lista de convidados ao FGB, aponta para uma direcionalidade nessa trama totalizante, dando significado à história do homenageado. Contribuem para essa construção de sentidos: o local escolhido, emblemático, a UNESP, onde atuou por quase 30 anos; a vinda de colegas de infância, de atuação profissional e de ex-alunos, propiciando a presença de três gerações. Viu-se a ênfase na identidade desse levantamento histórico sobre o violonista/compositor/ professor Bartoloni.

Muitas experiências de Bartoloni foram revividas no FGB e, com isso, a própria história do violão em São Paulo. O FGB trouxe à tona "eventos" adjacentes à trajetória de Bartoloni, que se mostraram cruciais para a história do violão de concerto brasileiro. Ricoeur aponta que um "evento" qualitativo pode produzir pontos de virada na narrativa, e como afirma Barros "pode assinalar o início de um processo, demarcar o seu fim, produzir uma mudança de curso, agregar mais movimento a um processo em andamento, estancar este processo, ou acrescentar ao relato um novo elemento informativo" (BARROS, 2012, p.8).

À maneira de historiador, os convidados escolheram eventos, argumentando-os em ordem. Vimos que cada um, seguindo as definições de Ricoeur, apoiou sua narrativa em referências reais, porém esta se estende da construção de quem narra à de quem ouve, ou seja, está plena de significados, recriando momentos vividos e aguardando uma ressignificação:

Com a narrativa histórica proposta por Ricoeur, o que se busca não é, portanto, mostrar meramente o que se passou, mas sim estabelecer uma referência a este vivido e depois retornar a ele. Emergindo do vivido, a narrativa a ele retorna, transformando-o e transformando-se em um único movimento, de tal maneira que se pode dizer que a narrativa histórica é uma reflexão do Vivido sobre si mesmo, através das imprescindíveis mediações do historiador que constrói o texto e da atividade recriadora do leitor que recebe e ressignifica a obra historiográfica, compreendendo, através dela, a si mesmo e ao mundo. (BARROS, 2012, p.16). 
Nesse enlace dos momentos apresentados no FGB com conceitos de Ricoeur, vemos verossimilhança entre a busca de dados pelo historiador, a narrativa por ele obtida, e a apreensão do receptor; os relatos no FGB foram plenos de levantamentos históricos, narrados e debatidos com a plateia, que já demonstrava in loco suas recriações das narrativas apresentadas, por meio de perguntas. Apoiado pela perspectiva de Ricoeur - no processo de interpretar narrativas construídas, admitindo-se tanto o individual quanto o coletivo - o método de investigação conhecido por "história de vida" e a pesquisa (auto) biográfica são conceitos para a nossa interpretação do FGB. Como esclarecem Passeggi et al:

(...) não se trata de encontrar nas escritas de si uma "verdade" preexistente ao ato de biografar, mas de estudar como os indivíduos dão forma a suas experiências e sentido ao que antes não tinha, como constroem a consciência histórica de si e de suas aprendizagens nos territórios que habitam e são por eles habitados, mediante o processo de biografização.

(...) Assim, conhecer, ouvir, ler a vida do outro é um modo de formação. (PASSEGGI ET AL, 2011, p.371)

Soubemos no FGB que os estudos violonísticos de Bartoloni iniciam na infância, por depoimento próprio, reiterado por colegas, em aulas particulares com Henrique Pinto, em ambiente informal (a casa do professor). O ambiente não-formal surge com a frequência a récitas de colegas ou rodas de violonistas (à casa de Ronoel Simões, na capital paulista). A graduação em Música é um ponto de virada para o ambiente formal, que irá leva-lo ao nível de Livre-docente. Tais transições da sua formação inicial à graduação, ao Mestrado e desse ao Doutorado foram apresentadas como marcos em sua carreira, ao encontro do que afirmam Passeggi et al sobre esses momentos como

etapas de transição estatutária e identitária, suscetíveis de se revelarem nas escritas de si, seja em gêneros acadêmicos autobiográficos já consagrados na tradição da universidade brasileira como dispositivos de (auto) avaliação, tais como os memoriais acadêmicos e de formação (...), a escrita de si é considerada como um 
dispositivo mediante o qual a pessoa que escreve é levada a refletir sobre seu percurso de formação formal, não-formal e informal. Consideramos que escrever e interpretar o que foi significativo para determinar modos de ser, seja como aluno seja como professorpesquisador-orientador, são, ao mesmo tempo, atividades formadoras e podem dar acesso ao mundo da academia visto pelos olhares de seus protagonistas (PASSEGGI ET AL, 2011, p.373).

Esse "olhar de protagonista" de Bartoloni - que com certeza passou parte de sua carreira acadêmica entre relatórios de pesquisa, memoriais (auto)descritivos e inúmeros currículos - perpassa aos colegas e participantes do FGB, que o continuam e narram ao público "eventos" da sua trajetória, baseando-se em résumés, ementas, dissertação, tese, livros resultantes, ou seja, reutilização do material um dia construído por Bartoloni, e agora, certamente, relido pelo olhar desses convidados, participantes e público. O que uma pessoa decide colocar em relevo para uma (auto)biografia é o essencial, ou, como denominam, o "fato biográfico"; citando Christine Delory-Momberger (2008), Passeggi et al afirmam que, para essa autora,

(...) o fato biográfico é esse viés que acompanha tudo o que percebemos e compreendemos ao longo de nossa vida. Trata-se de um espaço-tempo interior, que preexiste à escrita efetiva, mas que encontra na narrativa sua forma de expressão, a ponto de confundir-se com ela. Na narrativa de si, como ato autopoiético, o autor vai construindo uma figura de si, no exato momento em que se anuncia como sujeito e se enuncia como autor de sua história (PASSEGGI ET $A L, 2011$, p.381).

Soma-se a isso o conceito de auto-relato, "um locus privilegiado do encontro entre a vida íntima do indivíduo e sua inscrição numa história social e cultural. A biografia, ao tornar-se discurso narrado pelo sujeito autor e protagonista, instaura sempre um campo de renegociação e reinvenção identitária" (CARVALHO, 2003, p.284). Complementando a relevância da narrativa e do auto-relato está o Tempo, ou os níveis de tempos, como informa Carvalho, retomando o 
conceito de círculo trifásico de Ricoeur (mimeses I, II e III), que transpassa o ato narrativo, que então passa de um tempo prefigurado da ação,

no nível do vivido e da experiência em mimese I, para um tempo configurado simbolicamente pela composição narrativa em mimese II, tendo em vista comunicar uma experiência a alguém, o que caracteriza o terceiro tempo enquanto tempo da alteridade, onde se comunica o narrado para alguém. Assim, tem-se o tempo refigurado em mimese III, que restitui à ação o tempo vivido do leitor, completando o ciclo dessas operações narrativas, onde o sentido nunca se encerra num fechamento ou cristalização (CARVALHO, 2003, p.289).

A mimese aqui tratada não se configura como imitação, mas como tomada de consciência do fato biográfico, compartilhada tanto por narradores quanto por receptores. Essa é uma integração que ultrapassa construções individuais e meramente factuais; trata-se de elos "entre sujeito e história bem como entre os acontecimentos e sua reconfiguração na tessitura de vidas narradas" (CARVALHO, 2003, p.293). Um consagrado autor nesse viés, apontado por Carvalho, é Pierre Bourdieu (1930-2002), cujo trabalho sobre "história de vida"

descreve uma série de posições ocupadas pelo mesmo agente (ou um mesmo grupo) em estados sucessivos no campo a que pertence. Tomando o conceito de campo social como um espaço de relações materiais e simbólicas onde se posicionam os sujeitos.

(...) A noção de biografia (...) opera com a idéia de que os indivíduos são atravessados por movimentos culturais e processos históricos involuntários.

(...) não está em foco uma recuperação de dados biográficos de cunho individualista e psicológico, mas sim a reconstrução, através dos relatos autobiográficos, da trajetória histórica e cultural de um determinado grupo, ou ainda, das forças que constituem um campo social (CARVALHO, 2003, p.294). 


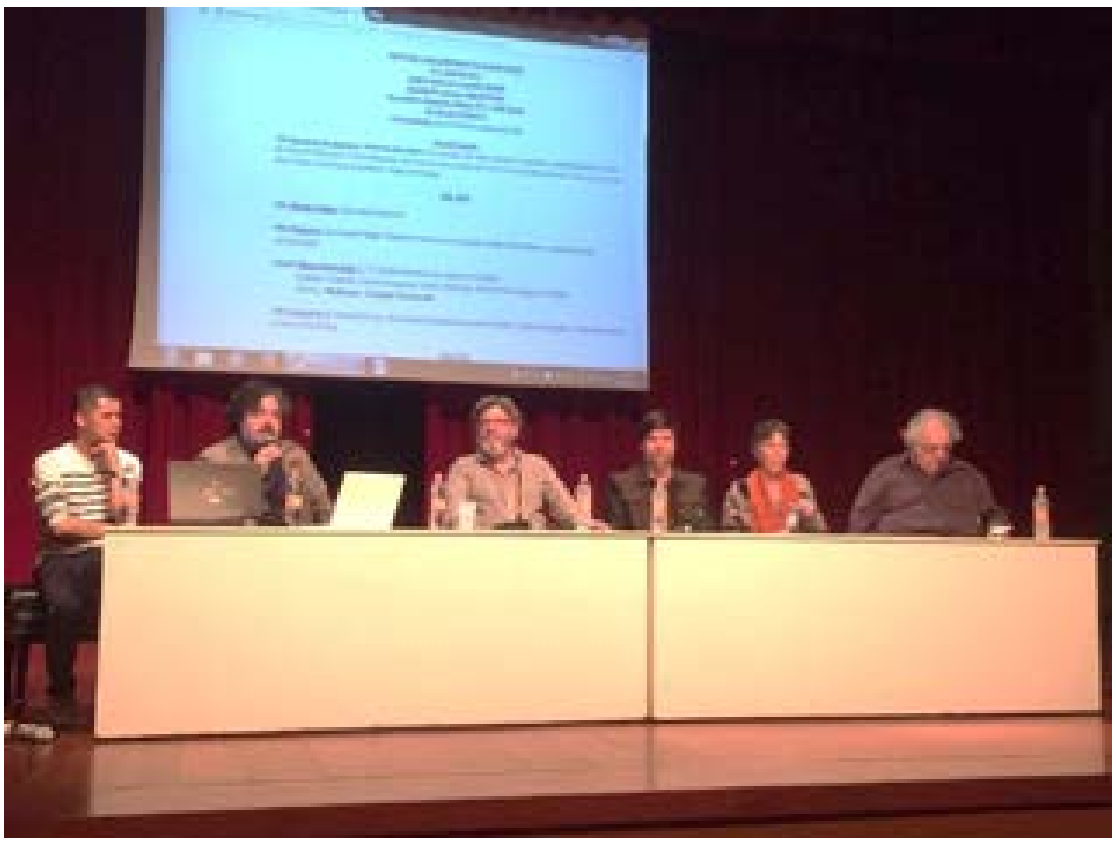

Figura 01. Mesa-redonda "Violão Paulista nos últimos 30 anos", da esquerda para a direita: Gilson Antunes, Cleyton Fernandes, Paulo Porto Alegre, Gisela Nogueira e Edelton Gloeden. Foto: Fabio Bartoloni.

Vimos considerações de convidados e participantes feitas fundamentalmente para se comunicar com a plateia do festival, apoiando-se em apontamentos para relatar a história de vida de Bartoloni, colaborando para recriar informações, posto que ao descrever "situações de vida, e argumentar sobre problemas significativos e recorrentes em sua vida e como ele/ ela se relaciona com isso" é que o interlocutor integra "o circuito dialógico da produção do conhecimento" (CARVALHO, 2003, p.295). Carvalho aponta ainda o trabalho de Edward Bruner, que organizou os processos da pesquisa biográfica em quatro níveis:

O primeiro é o relato dos povos e/ou sujeitos estudados sobre si mesmos (auto-relato). O segundo é o do pesquisador em seu diário de campo. O terceiro é aquele que o pesquisador faz para sua audiência (colegas/academia), com quem enriquece sua análise 
para uma posterior publicação. O quarto pode ser considerado como aquele dos pesquisadores/leitores do trabalho, que o sumarizam e o discutem em suas próprias salas de aula e publicações. Assim, estamos sempre recontando as mesmas histórias e ao mesmo tempo recriando-as. (CARVALHO, 2003, p.297).

Um pouco de cada nível pôde ser sentido durante o FGB. Além disso, na operação de comunicar, reinterpretar, recriar a (auto)biografia como narrativa localizam-se outras: percebemos que vários nomes foram elencados e tiveram de ser minimamente situados dentro da história de vida de Bartoloni para gerar sentido a suas próprias produções, como as biografias de Isaías Sávio (1900-1977) Henrique Pinto, Guido Santórsola e Abel Carlevaro.

Em acordo com os termos apontados por Carvalho, podemos sustentar que a área de atuação, artística nesse caso, já é em si um "campo social" que antecipa ou cria expectativas na comunidade, podendo ter ele mesmo sua identidade narrativa, dando margem a cumplicidades, consensos que ajudam a delimitar o campo, e por vezes podem inferir em questões-chave, como a questão trabalhista, muito presente - Como viver de música? Como conciliar horas de estudo e trabalho? Quais os espaços possíveis de atuação? Neste sentido, o FGB porvezes reforçou ou confrontou tais ideias dessa identidade narrativa (do campo artístico), partindo ora do homenageado, ora dos convidados ora do público.

\section{ATIVIDADES DO FGB: REFLEXOS DE GERAÇÕES}

Giacomo Bartoloni abriu o Festival em concerto com obras clássicas de Fernando Sor (1778-1839), Napoleón Coste (1805-1883), e modernas de Leo Brouwer (1939-) - este compositor que é sua grande influência musical -, além de composições próprias, como Ditirambo, premiada em 1979 no Concurso do Seminário Palestrina. Na segunda parte da abertura, o Duo Lucatelle-Bartoloni, formado por Daniela Lucatelle (piano) e Fábio Bartoloni (violão), subiu ao palco e o concerto seguiu com variadas formações, com obras de Villa-Lobos (1887-1959), Carmo Bartoloni (irmão de Giacomo) 
e destaque para duas estreias mundiais: Valsa para piano solo de Giacomo Bartoloni e Divertimento Mediterraneo para dois violões, do compositor italiano radicado em Londres Luca Luciano, obra esta encomendada em razão do festival.

Nessa abertura do FGB, vê-se uma identidade buscada, a do homenageado, como oriundo do violão de concerto, de formação clássica, porém aberto a autores que buscaram pontos de mudança, como Villa-Lobos e Brouwer. Essa identidade é, sem dúvida, corroborada por colegas de sua geração, que passaram pelos mesmos acontecimentos, porém, de forma subjetiva, é mais acentuado em Bartoloni um perfil clássico-moderno ${ }^{3}$.

No segundo dia, um masterclass de Giacomo abriu os trabalhos. Em seguida, a palestra de Teresinha Prada sobre a extinta revista Violão Intercâmbio, mostrando a participação de Bartoloni. Prada relatou o contexto em que surgiu a revista, fruto do // Encontro Nacional de Violonistas (UNESP, setembro/1993), organizado por Bartoloni, que, na plenária final do Encontro, sugeriu a criação de um informativo que reunisse notícias do violão de concerto. Um mês depois, sairia o primeiro número de Violão Intercâmbio - nome sugerido por Teresinha Prada em parceria com Giacomo. Como professor da UNESP, ele viabilizou a edição do informativo, o endereço para correspondência. Do segundo número em diante, o informativo já contava com a colaboração de Gilson Antunes e seria ampliado com o passar do tempo, com o trabalho de Ricardo Marui.

Como ex-aluna de Bartoloni na UNESP, Teresinha Prada narrou acontecimentos já distanciada temporalmente, sinalizando a importância desse veículo na difusão do violão nos anos 1990. Foi grande o debate com a plateia; os mais jovens compararam a revista às redes sociais atuais, e discutiram espaços de atuação e como viver de música ontem/hoje, sendo a preocupação com a formação musical e a manutenção de uma carreira aspectos bem discutidos; já o público mais velho valorou a revista por haver então pouco acesso a informações e por ser um reflexo da geração, simbolizando o ambiente do violão nacional.

Tal debate parece reiterar o "tempo refigurado" (termo ricoueriano), que traz de volta tempos vividos, por quem viveu

\footnotetext{
${ }^{3}$ Entendemos por perfil clássico-moderno os músicos com repertório tradicional que, no entanto, buscam obras modernas e de compositores vivos para integrar seus repertórios.
} 
e completou o ciclo de operações narrativas, embora o sentido continue aberto, não cristalizado, pelo viés da audiência. A necessidade de autogerenciar uma carreira foi o ponto reforçado em mesa e discussão, sendo a revista Violão Intercâmbio, centro do debate, vista como uma atitude tomada, uma resposta, perante dificuldades de informação e divulgação daquele momento.

A mesa-redonda "O violão paulista nos últimos 30 anos" trouxe Edelton Gloeden (USP); Sidney Molina (FIAM-FAAM Centro Universitário); Gilson Antunes(Unicamp); Paulo Porto Alegre(Escola de Música do Estado de São Paulo - Tom Jobim, EMESP) e Gisela Nogueira (UNESP), mediada por Cleyton Fernandes (Universidade Federal do Cariri). Pela fala dos participantes, consideramos que o estabelecimento do violão na cidade de São Paulo (irradiando para o interior) se deu mormente pelo trabalho do uruguaio Isaías Sávio, como realizador de eventos, catalisador de uma didática, um grande número de alunos, que se tornariam concertistas e professores de futuras gerações, bem como seus contatos internacionais com Carlevaro e Santórsola. Sávio também circulou no meio violonístico do Rio de Janeiro, mantendo contato com o Duo Abreu 4 .

Após Sávio, Henrique Pinto foi o grande nome, unanimidade entre os participantes da mesa. Outras figuras destacadas foram os violonistas argentinos Jorge Martínez Zárate (1923-1993), Graciela Pomponio (1926-2007) e Miguel Angel Girollet (1947-1996). O evento mais aclamado pela mesa foram os Seminários Palestrina (Porto Alegre - RS, década de 1970), como fonte de informação que inspirou outras ações, como os encontros no Conservatório Brooklin Paulista, cujo trabalho realizado (masterclasses, concertos, convidados estrangeiros) impressionou pela ressonância e modelo replicado em outras gerações.

Essa mesa redonda, a nosso ver, recriou momentos e reiterou posições alcançadas pelo processo de "recriação biográfica" (modelo de Bruner supracitado) permeando o auto-relato e o diálogo com colegas para um mesmo acontecimento, como nos momentos em que imprecisões foram dirimidas e relatos completados entre os participantes, além da ideia de "campo social" (Bourdieu) pela alternância de falas entre os sujeitos que

\footnotetext{
${ }^{4}$ Famoso duo brasileiro de violão clássico, formado pelos irmãos Sérgio e Eduardo Abreu, de carreira internacional na década de 1970.
} 
ali estavam em uma condição de representantes, de sujeitos da trajetória de Bartoloni e, por extensão, da história do violão paulista. Mais uma vez, a preocupação com a formação da carreira foi debatida com a plateia, que comparou modelos de eventos violonísticos na divulgação de carreiras.

Ao fim do dia, um concerto contou com as presenças de Ângela Muner, Teresinha Prada, Rosimary Parra, Gisela Nogueira, Luciano Morais e Edelton Gloeden proporcionando um panorama da música de Bartoloni, bem como um repertório que ao longo de seu trabalho como docente ele privilegiou, como Heitor Villa-Lobos, Leo Brouwer, Abel Carlevaro, o erudito espanhol e vertentes da música contemporânea. Acreditamos que os concertos também foram um modo de narrar a trajetória de Bartoloni, ao recriar em performances suas escolhas estéticas como docente na UNESP.

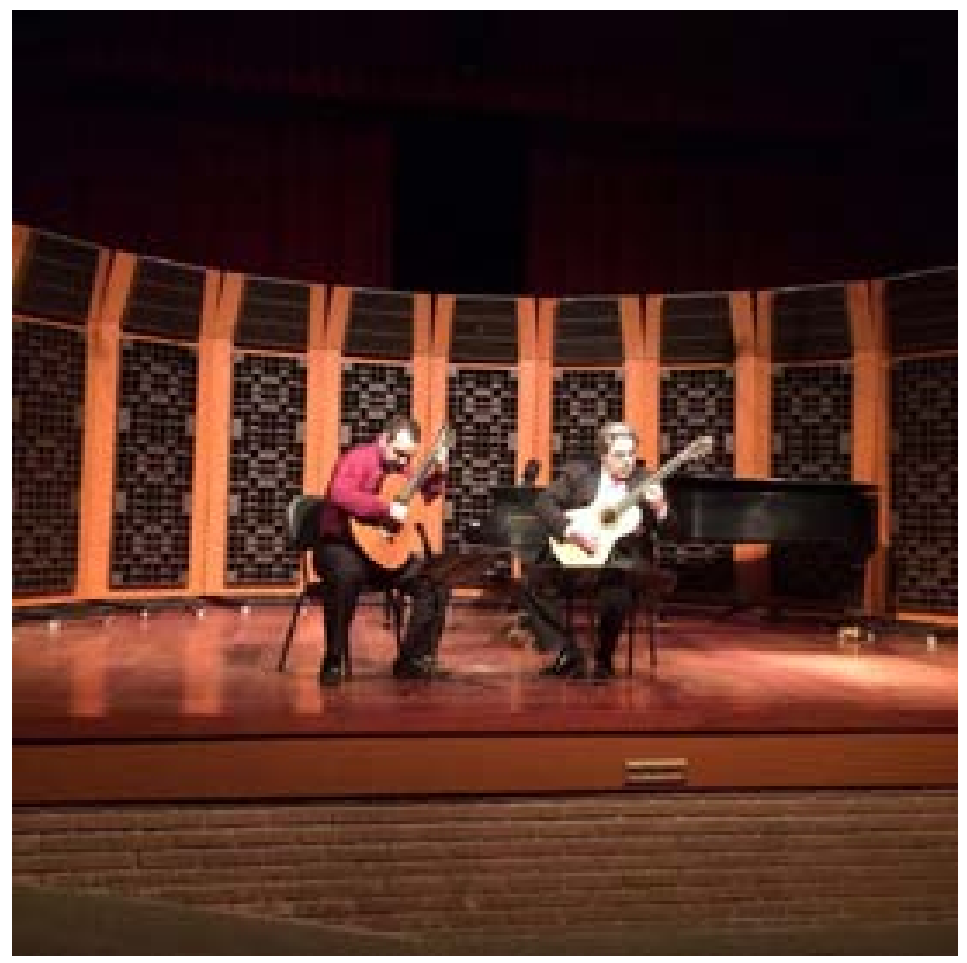

Figura 02. Duo Fábio e Giacomo Bartoloni no recital de abertura do Festival. 
Para encerrar o FGB, no terceiro dia houve dois concertos e a mesa-redonda "Trajetória de Giacomo Bartoloni Violonista", que contou com a presença de Everton Gloeden, Teresinha Prada, Juliana Oliveira e Luciano Morais, mediada por Fábio Bartoloni. Everton Gloeden (EMESP; Brazilian Guitar Quartet) relembrou importantes fatos da formação de Giacomo, quase como testemunha, posto que Everton passou por eventos em comum: o início com Henrique Pinto, a ida aos Seminários Palestrina, o ambiente de muito entusiasmo, como a presença marcante de Carlevaro e Santórsola.

Em seguida, Teresinha Prada reiterou a relevância de Giacomo compositor, lembrando que é uma tradição do meio violonístico desde o período clássico a presença de violonistas-compositores, como atividade contígua ao músico, ser intérprete e compositor; nesse sentido, Bartoloni seguiu essa linha, produzindo obras e apostilas. No caso, a atração pela obra de seus ídolos, como Leo Brouwer, o levou a compor. Observando Bartoloni-violonista, Prada apontou um viés forte em música contemporânea e latino-americana. Lembrou que em 1970, o convívio com Santórsola, a partir dos Seminários Palestrina, e depois em São Paulo, causou impacto em sua futura abordagem musical com seus alunos. Na técnica, o entusiasmo veio também com o trabalho de Carlevaro, como já comentara Everton Gloeden.

Luciano Morais(UNESP) trouxe para a discussão a necessidade da compreensão da academia (a Universidade) na trajetória de Bartoloni, bem como de outros de sua geração, que reposicionaram a atividade musical em frentes como a pesquisa e a extensão (posto que a docência já se realizara plenamente pelas gerações anteriores). Nesse ponto, Morais dimensiona a pesquisa como função inerente à formação musical, a cada vez que um docente solicita de seu discente a busca por referências, gravações, leituras complementares às obras. E a extensão, a cada vez que concertos, récitas ou palestras são realizados ou apreciados, fechando o tripé que a Universidade propugna, em sintonia com uma carreira musical. Finalizando, Juliana Oliveira (Conservatório de Tatuí - SP) exortou a presença constante de Bartoloni na formação musical de muitos violonistas na cidade de Tatuí e entorno, que possui um dos melhores Conservatórios do Brasil. 
Já essa mesa redonda, acreditamos, foi o momento de maior articulação entre o que cremos ser a conceituação de narrativas e sentidos. Os momentos miméticos (termo de Ricouer) foram narrados de participante em participante para/com a plateia, em busca de situar o tempo vivido da formação de Bartoloni, como foi atingido e de como agiu na esteira dos fatos (narrativos). O interessante foi ver o caminho do tempo prefigurado da ação (no caso aqui a trajetória do homenageado) ao momento da mimese III, quando o ciclo das operações narrativas se contorna na reação da plateia, que aprimorou a experiência formativa de Bartoloni, comparando-a aos momentos atuais, identificando aqueles pontos de contato com grandes nomes, ao passo que hoje há todo um circuito que trata de maneira profissional a vinda de grandes nomes do violão.

Se a mesa sobre os 30 anos do violão paulista relatou aspectos daquele tempo-espaço musical, a mesa sobre a trajetória de Bartoloni já demonstrou o ponto de virada do violão, pelo ingresso deste na Universidade como curso superior, saindo da condição de instrumento à margem da cena musical de concerto.

De volta aos concertos do FGB, Fábio Bartoloni, Filipe Marllon, Luís Stelzer, Gilson Antunes e o Duo Favoritti (Dagma Eid e Patrícia Nogueira, vindas de Tatuí) revezaram-se no palco apresentando repertório variado. No encerramento do FGB, Everton Gloeden abriu a noite tocando J. S. Bach, Luís Stelzer voltou ao palco em duo com Ricardo Luccas (que também se apresentou solo), seguindo-se performances de Cleyton Fernandes, Flávio Apro e de Giacomo Bartoloni com os flautistas Eduardo Monteiro e Celina Charlier. Uma presença ilustre na plateia foi do compositor Edmundo Villani-Côrtes (1930-), ex-colega de Giacomo no departamento de música da UNESP. Pode-se afirmar que todos os concertos reuniram violonistas de três gerações, abrangendo o erudito e o universo da música instrumental, e como dissemos, acreditamos que as performances, a seu modo, também tratam da trajetória do homenageado. 


\section{O COMPOSITOR GIACOMO BARTOLONI}

Durante o FGB por várias vezes surgiu o debate de como conciliar o trabalho docente e a atuação no meio artístico. As obras de Giacomo Bartoloni materializam essa realidade; professor/ pesquisador/artista se simbiotizaram, em um esforço por produzir. Tal produção, a seguir analisada, reflete pontos das narrativas supracitadas, momentos como a ascensão de Leo Brouwer no meio violonístico, da diversidade da atuação musical - necessitando se autogerenciar - e da admissão do violão na universidade, frisando que na UNESP Bartoloni teve muito contato com outros compositores. Bartoloni compôs obras para violão solo, duo, trio e quarteto de violões e duo de violino e violão. A obra para violão solo foi composta ao longo de 40 anos, entre 1976 e 2016:

- 3 Estudos (1976)

- Elíptica (1978), originalmente Estudo n.4

- Ditirambo, homenagem a Brouwer (1979)

- 4 Canções: n.1 (1988), n.2 (1997), n.3 (2001) e n. 4 (2006)

- Tango Martes (1988)

- Sonata Retratos (2016)

Com exceção da Canção . $^{\circ} 4$, todas estas obras foram interpretadas ao longo do FGB. O próprio Bartoloni tocou as seguintes peças em seu concerto: 3 Estudos, Canções 1, 2 e 3 e Ditirambo. A peça Elíptica foi interpretada duas vezes, pelos violonistas Edelton Gloeden (em 10 de agosto) e Ricardo Luccas (em 11 de agosto). Tango Martes foi interpretada por Flávio Apro e a Sonata Retratos, sua mais recente composição, por Fábio Bartoloni. Apesar de não ter sido executada ao longo dos concertos, a Canção $n .^{\circ} 4$ fez parte do vídeo de introdução do FGB, que era mostrado antes das atividades, por isso consideramos que sua obra completa para violão solo foi apresentada integralmente.

Além disso, duas peças para duo de violões e uma para violão e flauta foram tocadas. A versão de Gnattaliana para dois violões (a versão original foi composta em 2000 para trio de violões) foi tocada por Giacomo e Fábio Bartoloni no concerto de abertura. A Fantasia del Tambor (1988) foi interpretada por dois duos: Gisela Nogueira e Luciano Morais (em 10 de agosto) e Dagma Eid e Patrícia Nogueira (em 11 de agosto). No encerramento, Giacomo Bartoloni e a flautista Celina Charlier executaram uma versão inédita da peça 
7 Rituais, composta em 1995, originalmente para violino e violão.

Bartoloni nunca estudou Composição formalmente, quer seja em alguma escola ou em aulas particulares. Em sua formação musical, considera muito importante as aulas que teve com Guido Santórsola. Italiano naturalizado uruguaio, Santórsola compôs diversas obras para violão solo e música de câmara com violão. Bartoloni teve aulas com ele primeiramente em Porto Alegre, nos Seminários Palestrina, e posteriormente em São Paulo em cursos organizados pelo professor Henrique Pinto. Àquela altura dos anos 1970, Santórsola já havia composto muitas peças para violão, mas suas aulas eram mais voltadas a aspectos estéticos e de interpretação, não envolvendo estudos sobre como compor (BARTOLONI, 2004, p.125).

Outrossim, ao longo de seu período como professor de violão da UNESP, Bartoloni pôde conviver e trocar ideias com diversos compositores, tais como Nílson Lombardi (1926-2008), Edmundo Villani-Côrtes (1930-), Eduardo Escalante (1937-), Achille Picchi (1952-), Flo Menezes (1962-) e Edson Zampronha (1963-).

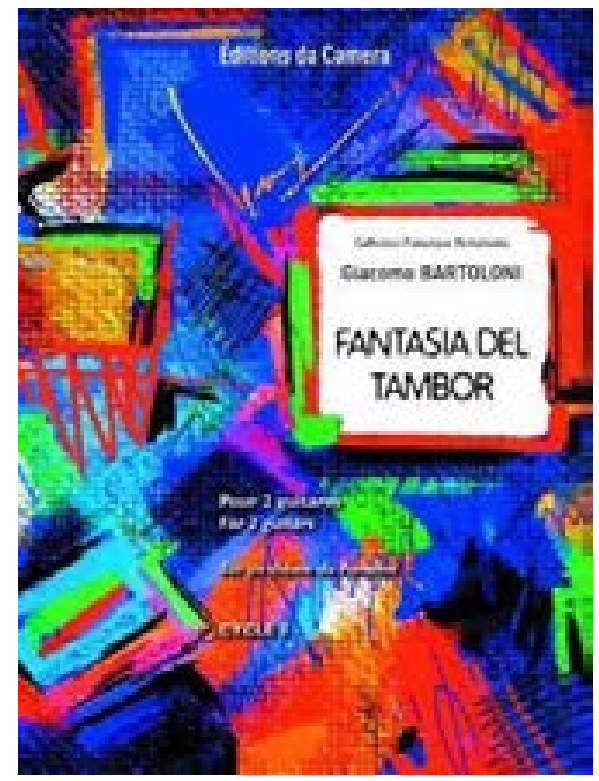

Figura 03. Capa da edição da Fantasia del Tambor para dois violões de Giacomo Bartoloni pela editora francesa Éditions da Camera. 
De fato, o compositor Giacomo Bartoloni nasceu de um desejo de expressar o impacto que ouvir a obra do compositor cubano Leo Brouwer lhe causou. Impressionado principalmente com obras da considerada segunda fase de composição do compositor cubano, Bartoloni compôs sua série de 3 Estudos em 1976, aos 19 anos de idade. Nesta época Brouwer, além de ser ainda ser um violonista atuante, compôs um conjunto de obras que viriam a marcar o repertório para violão no século XX, como por exemplo, Elogio de la Danza, La Espiral Eterna, Canticum e Tarantos.

Neste período, o compositor cubano mesclou toda a influência dos festivais no Leste Europeu, como o Outono em Varsóvia, que ele frequentou nos anos 1960, assistindo a estreias da vanguarda polonesa, além de sua experiência nos Estados Unidos, permanecendo lá cerca de um ano, e toda a bagagem musical que ele trouxe de Cuba, incluindo traços da cultura e da música popular caribenha (PRADA, 2008, p.110-111).

Como podemos verificar na lista de obras de Giacomo Bartoloni, estes estudos de 1976 foram o início de uma carreira de compositor que vem se desenvolvendo há pouco mais de 40 anos. Apesar desta continuidade, há de se notar que suas composições estão espaçadas ao longo dos anos, pois a atividade como compositor tem sido dividida com suas trajetórias como professor e intérprete. Mas apenas três anos após o início de sua carreira como compositor Bartoloni compôs a obra Ditirambo, homenagem a Brouwer. Esta obra foi premiada com o primeiro lugar do Concurso de Composição do Seminário Palestrina de 1979.

Ditirambo, homenagem a Brouwer tem estrutura formal similar a Elogio de la Danza de Brouwer, composta em 1964. Ambas obras possuem dois movimentos que contrastam seus andamentos, sendo a de Brouwer lento-rápido e a de Bartoloni, rápido-lento.

Elogio de la Danza de Leo Brouwer (1964)

I. Lento

II. Ostinato

Ditirambo, homenagem a Brouwer de Giacomo Bartoloni (1979)

I. Momentos

II. Final 
A própria referência ao Ditirambo, hino ou canção dionisíaca cantado entusiasticamente por um coro(DE OLIVEIRA e GERALDO, 2016, p. 59) vem da obra Canticum, composta por Brouwer em 1968, igualmente em dois movimentos. Há ainda uma citação do tema na Fuga n.1 (1957), também de Brouwer.

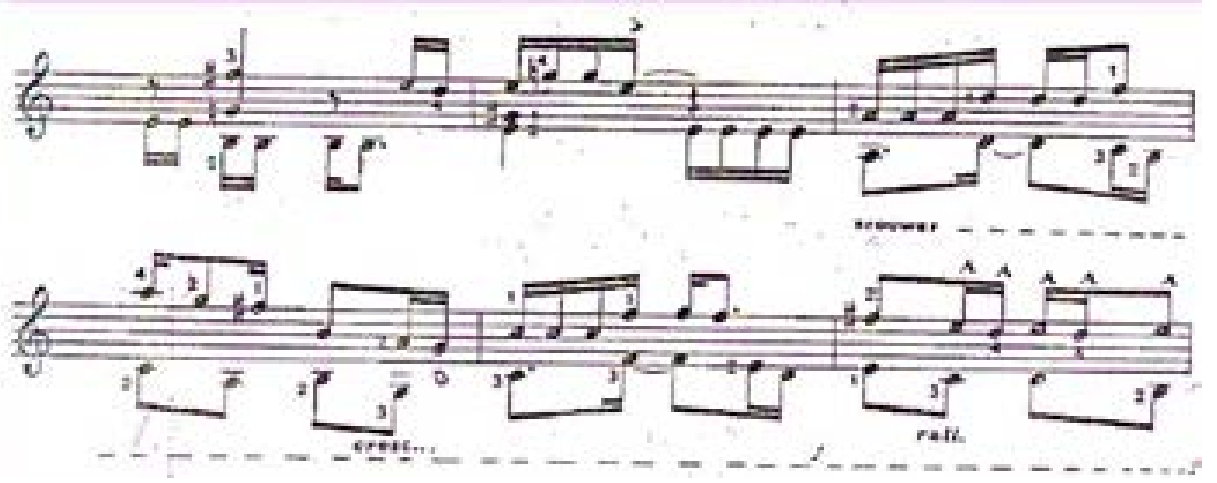

Figura 04. Trecho do segundo movimento do Ditirambo de Giacomo Bartoloni, onde há a citação do tema da Fuga n.1 de Brouwer

A obra foi publicada pela editora Ricordi Brasileira, como premiação do concurso. De acordo com o compositor, o título original foi alterado pelos editores para somente Ditirambo, pois o fato de Brouwer ser de Cuba poderia causar problemas com a censura pela ditadura militar que havia no Brasil. Este fato foi revelado publicamente durante o I Festival Leo Brouwer, organizado pela Universidade de São Paulo em 2008. A ocasião marcou a primeira vinda do cubano ao Brasil. Em um dos concertos do Festival, Bartoloni interpretou o Canticum de Brouwer e seu Ditirambo, onde pôde finalmente declarar publicamente, na presença de Brouwer, o título original da obra e a razão de ele ter sido modificado.

O festival de 2008 inspirou Bartoloni a compor uma nova peça que fizesse referência a Brouwer. A primeira ideia foi compor uma obra em quatro movimentos que utilizasse as quatro afinações da sexta corda do violão utilizadas por Brouwer: Fá, Mi, Mi bemol e Ré. Deste desejo nasceu sua Sonata Retratos, concluída em 2016. Mantendo a ideia das afinações, Bartoloni 
terminou por ampliar as referências a outros dois pilares do violão clássico no século XX: Manuel Ponce (1882-1948) e Mario Castelnuovo-Tedesco (1895-1968).

Sonata Retratos de Giacomo Bartoloni (2016)

I - Prólogo (Leo Brouwer entra no recinto)

II - Allegro (Brouwer evoca Ponce)

III - Scherzo (Brouwer e Ponce continuam o diálogo)

IV - Ponce chama Castelnuovo-Tedesco, intérprete e autores animam-se mutuamente

O primeiro movimento tem uma sonoridade que alude a Brouwer, servindo como prelúdio à obra. O segundo traz a Forma Sonata, mais tradicional formal e harmonicamente, inspirado por Ponce, principalmente sua Sonatina Meridional (1939). O terceiro é um scherzo que dialoga entre dois compositores, mas também representa um diálogo entre o repertório para violão da primeira metade do século XX, desenvolvido principalmente por Andrés Segovia (1893-1987) e do qual Ponce foi um dos mais ativos colaboradores, e o repertório da segunda metade do século, do qual o violonista Julian Bream foi um dos protagonistas e que faz parte de um cenário (que inclui Brouwer) de expansão do repertório no sentido de uma estética notadamente mais moderna.

O quarto e último movimento traz Castelnuovo-Tedesco à cena, inspirado por sua Sonata op. 77 (1934). Além disso, faz referência aos três primeiros movimentos e cita com uma variação rítmica o Estudo 5 da série de Estudos Sencillos de Brouwer.

\section{A A toditis $\sin 0$ \\ Sonatina meridional}

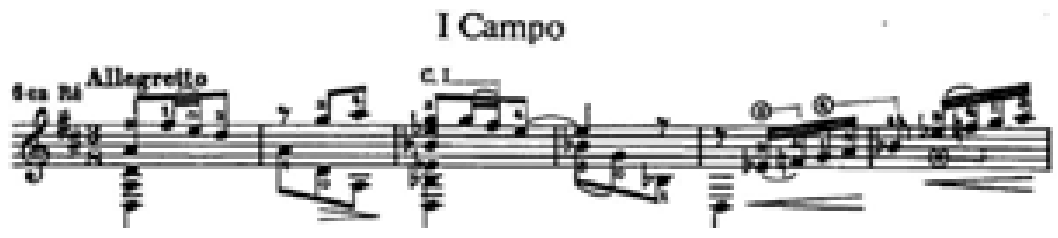

Figura 05. Motivo que inicia a Sonatina Meridional de Ponce 

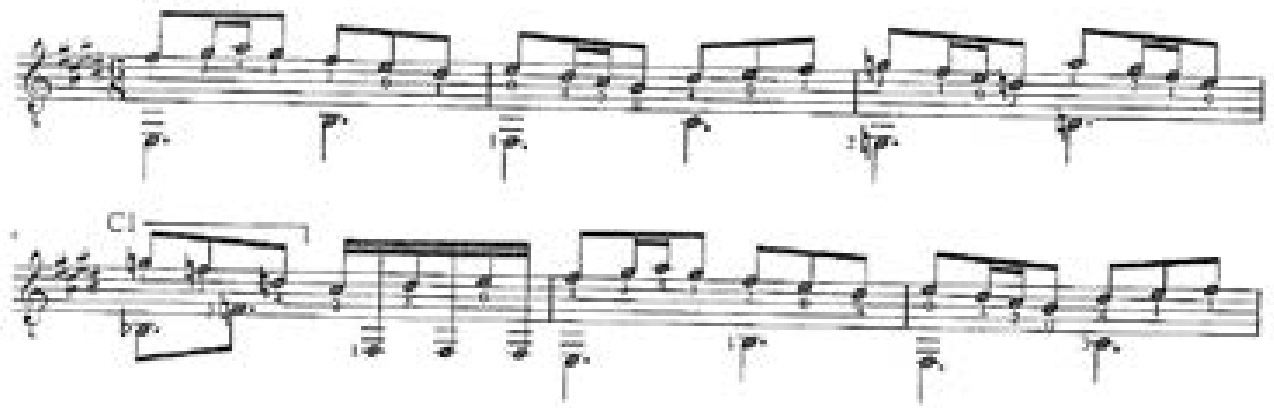

Figura 06. O motivo rítmico que inicia a Sonatina Meridional de Ponce é utilizado ao longo do segundo movimento da Sonata Retratos.
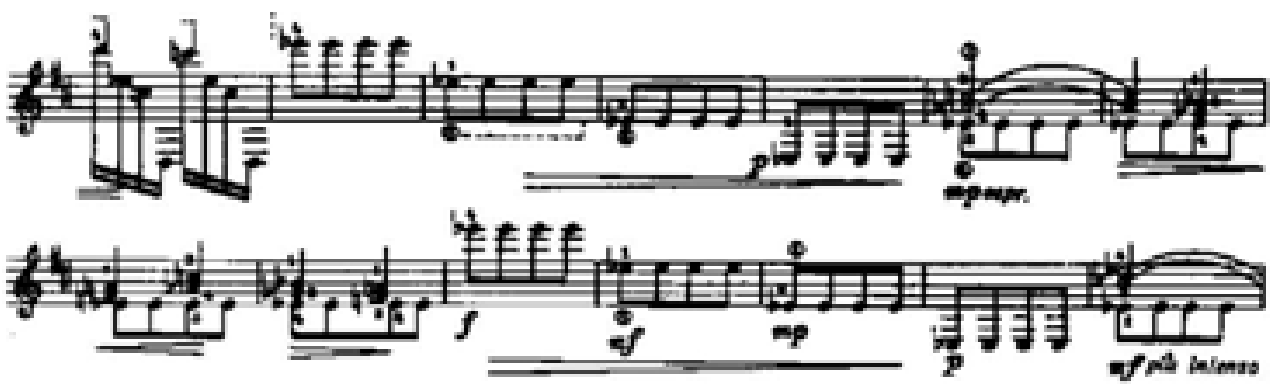

Figura 7. Sequência de oitavas descendentes a partir da nota Mi bemol do quarto movimento da Sonata op.77 de Castelnuovo-Tedesco

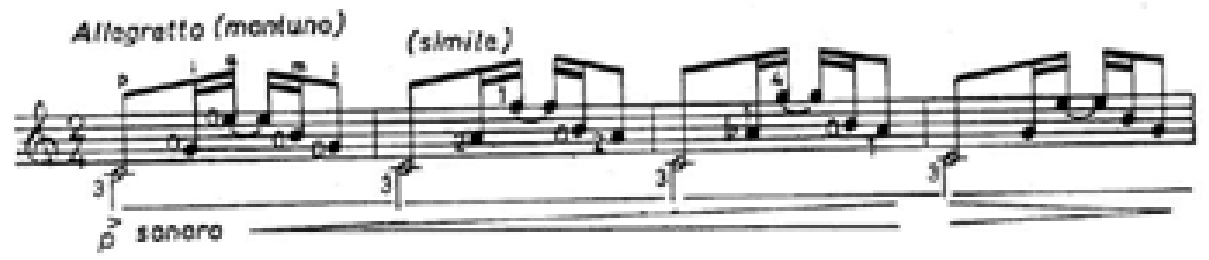

Figura 7. Sequência de oitavas descendentes a partir da nota Mi bemol do quarto movimento da Sonata op.77 de Castelnuovo-Tedesco 


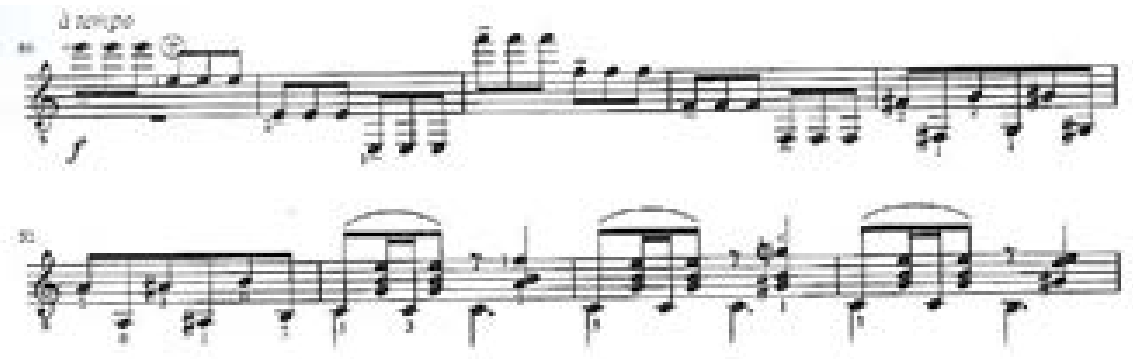

Figura 09. Bartoloni faz referência no quarto movimento de sua Sonata Retratos à sequencia de oitavas de Castelnuovo-Tedesco (embora o faça a partir das notas Mi e Fá) e também à harmonia que inicia o Estudo V de Brouwer.

Essa ampliação da homenagem a Brouwer para outros dois compositores pode ser enxergada como uma fase mais madura de Bartoloni compositor. O próprio Brouwer em sua terceira fase deixou de lado um certo radicalismo experimental e voltou a abarcar conceitos tonais mais tradicionais (PRADA, 2008, p.119). Temos que considerar que em 1979 Bartoloni era um jovem compositor inspirado pelo Brouwer da época, então diferente do Brouwer do período mais recente e de hoje. E foi este Brouwer, que podemos considerar mais abrangente, que inspirou a obra de 2016, composta por um também mais abrangente Bartoloni. Sabendo da admiração de Bartoloni por Brouwer, Edelton Gloeden, Gilson Antunes e Teresinha Prada interpretaram obras do cubano nos concertos, além do próprio homenageado.

\section{O COMPOSITOR GIACOMO BARTOLONI}

Acreditamos que o FGB apresentou contribuições para a cena acadêmica e musical. Como observado, foi uma deferência ao docente, ora aposentado, que fundou o bacharelado em violão dentro da UNESP em 1987 e que formou dezenas de profissionais ao longo de quase três décadas de serviços públicos prestados. O fato de ter ocorrido na própria UNESP deu substância ao evento, aquiescendo mais que uma formalidade, mas um marco histórico na trajetória da música/violão nessa universidade e na cidade de São Paulo. 
Ao admitirmos junto com os historiadores o conceito ricoueriano de que "toda história é narrativa" e que é uma reflexão do Vivido sobre si mesmo, cada fala do FGB corrobora a História do Violão em São Paulo, desde inícios do século XX até a década de 1980, e como isso se desdobrou ao longo dos anos 1990 e 2000, impactando o meio violonístico não só em São Paulo, mas em outras partes do Brasil, dado que alunos formados pela UNESP assumiram posições importantes em universidades por todo o país. Podemos considerar que além de discutir o passado, o FGB abordou a situação presente dos cursos de violão nas universidades brasileiras, bem como a própria situação destas instituições nos dias de hoje, demonstrando não a descrição estanque no ato de biografar o homenageado e seu entorno ali no FGB, mas como os sujeitos deram forma a suas experiências e sentidos transbordados.

Giacomo Bartoloni possui uma carreira rica e variada como professor, instrumentista, compositor e acadêmico, cujos memoriais acadêmicos e de formação foram ali levantados. Assim como o homenageado, o Festival foi um campo de renegociação e reinvenção identitária que construiu sua biografia, pelo discurso narrado pelos sujeitos, inclusive as facetas e possibilidades de se pensar sobre música na universidade, contendo discussões sobre história, performance, criação e educação musical. O FGB possibilitou preservar a memória e contribuir para o reconhecimento de etapas à comunidade musical universitária, ali presente, no mínimo, por duas gerações além à do homenageado.

Identificamos no evento a importância da rara homenagem em vida a um artista, mas além disso o reflexo de uma geração que, ali reunida, transmitiu uma narrativa, que por sua vez foi digerida pelo avanço temporal e pela tomada de consciência em um espaço altamente especial, simbólico, tal seja, o da academia e da própria história do homenageado, a UNESP.

Debatendo as dificuldades culturais da carreira musical e dentro da universidade, as muitas dificuldades burocráticas que a mesma impõe, demonstraram-se lados opostos às vezes, mas que podem ser atuações complementares se assim trabalhadas, encaradas como ato contínuo, do ensino à extensão e à pesquisa. Mostras dessas confluências foram 
dadas tanto pelos concertistas atuantes na academia, quanto pelo fato de o homenageado ser professor, compositor premiado, cujas obras foram postas em relevo aqui para justamente estampar a possiblidade de desempenho múltiplo.

Em muitos momentos no FGB, o homenageado assumiu a fala com um tom de conscientização, próprio de quem já releu vários pontos de sua trajetória com o devido distanciamento temporal. Ao mesmo tempo, demonstrou ter tido ele mesmo um caminho contínuo a vários colegas de sua geração e, com isso, responder a dúvidas de muitos estudantes na plateia, campo social desse determinado grupo, onde o binômio formação-manutenção de uma carreira artístico-musical parece ter sido a grande pergunta que o FGB teve que debater. 


\section{REFERÊNCIAS}

BARROS, José D'Assunção. Tempo e Narrativa em Paul Ricoeur: considerações sobre o círculo hermenêutico. In: Fênix - Revista de História e Estudos Culturais: NEHAC/Instituto de História da Universidade Federal de Uberlândia, v. 9, ano IX, Janeiro/Fevereiro/Março/Abril de 2012, pp. 01 - 27. Disponível em http://www.revistafenix. pro.br/PDF28/Artigo 9 Jose_D Assuncao Barros.pdf. Último acesso em 29 de agosto de 2017.

BARTOLONI, Fábio Figueiredo. Guido Santórsola: Uma Introdução à obra violonística e seu trabalho como professor para o violão brasileiro. 2004. Dissertação de mestrado em música. UNESP, 2004.

CARVALHO, Isabel C. M.. Biografia, identidade e narrativa: elementos para uma análise hermenêutica. Horiz. antropol., Porto Alegre, v. 9, n. 19, p. 283-302, Julho 2003. Disponível em http://www.scielo.br/scielo.php?script=sci arttext\&pid=S0104-71832003000100012\&lng=en\&nrm=i so. Acesso em ago. 2017.

DE OLIVEIRA, Flávio Ribeiro; GERALDO, Lidiana Garcia. Ditirambo: Culto e Louvor a Dioniso. Revista Hélade, Rio de Janeiro, v 2, n.3, p. 59-60, dez. 2016. Disponível em $<$ http://www.helade.uff.br/v2n3/helade_v2_n3_flavio_e lidiana.pdf >. Acesso em dez. 2017.

PASSEGGI, Maria. da C. ; SOUZA, Elizeu C. de; VICENTINI, Paula P.. Entre a vida e a formação: pesquisa (auto) biográfica, docência e profissionalização. Educ. rev., Belo Horizonte, v. 27, n. 1, p. 369-386, abr. 2011. Disponível em http://www.scielo.br/scielo.php?script=sci_ arttext\&pid=S0102-46982011000100017\&lng=pt\&nrm=i so. Acesso em ago. 2017.

PRADA, Teresinha. Violão: de Villa-Lobos a Leo Brouwer. São Paulo: Terceira Margem, 2008. 